\title{
marges Marges
}

revue d'art contemporain Revue d'art contemporain

23 | 2016

Globalismes

\section{Fabien Mérelle}

Umut Ungan

\section{(2) OpenEdition}

Journals

Édition électronique

URL : http://journals.openedition.org/marges/1211

DOI : 10.4000/marges.1211

ISSN : 2416-8742

\section{Éditeur}

Presses universitaires de Vincennes

\section{Édition imprimée}

Date de publication : 20 octobre 2016

Pagination : 112-132

ISBN : 978-2-84292562-8

ISSN : 1767-7114

Référence électronique

Umut Ungan, «Fabien Mérelle », Marges [En ligne], 23 | 2016, mis en ligne le 20 octobre 2018, consulté le 15 septembre 2020. URL : http://journals.openedition.org/marges/1211 


\section{Fabien Mérelle}

" C'est comme être attrapé par une plante vénéneuse. Mes dessins sont apparemment simples mais quand on plonge dedans, il faut ouvrir les tiroirs. Ma raison de dessiner est dans le détail. ".

Entretien avec Xavier Renard, La Croix, 9 septembre 2015.

L'objet principal des dessins de Fabien Mérelle de ces deux dernières années est constitué d'une manière générale de son environnement social immédiat (sa famille) et ses états d'âme, si l'on peut dire. La relative proximité des thèmes choisis pour illustrer cet espace vital se conjugue avec la forte distance instaurée devant les personnages dépouillés de leurs décors et la fantaisie des scènes qui les animent, tout en gardant une forte identité à travers leurs habits ainsi que le détail réaliste de ses traits. C'est en ce sens qu'ils revêtent un caractère presque allégorique avec un certain degré d'expressivité, qui déplace l'attention des figures dessinées à des instants forts, avec les affects qui les imprègnent d'une manière explicite ou implicite. Tout en discernant des choses du monde et des attitudes, celui/ celle qui regarde peut ainsi se projeter librement dans les représentations, qu'elles relèvent des moments du quotidien ou de ceux davantage rêvés.

Né en 1981, Fabien Mérelle est diplômé l'École Nationale Supérieure des Beaux-Arts de Paris en 2006. Il est ancien pensionnaire de la Casa Velazquez à Madrid. Son travail a été régulièrement exposé dans les galeries Praz-Delavallade à Paris, Édouard Malingue à Hong Kong, Michel Soskine et Guy Bärtschi à Genève.

Umut Ungan 


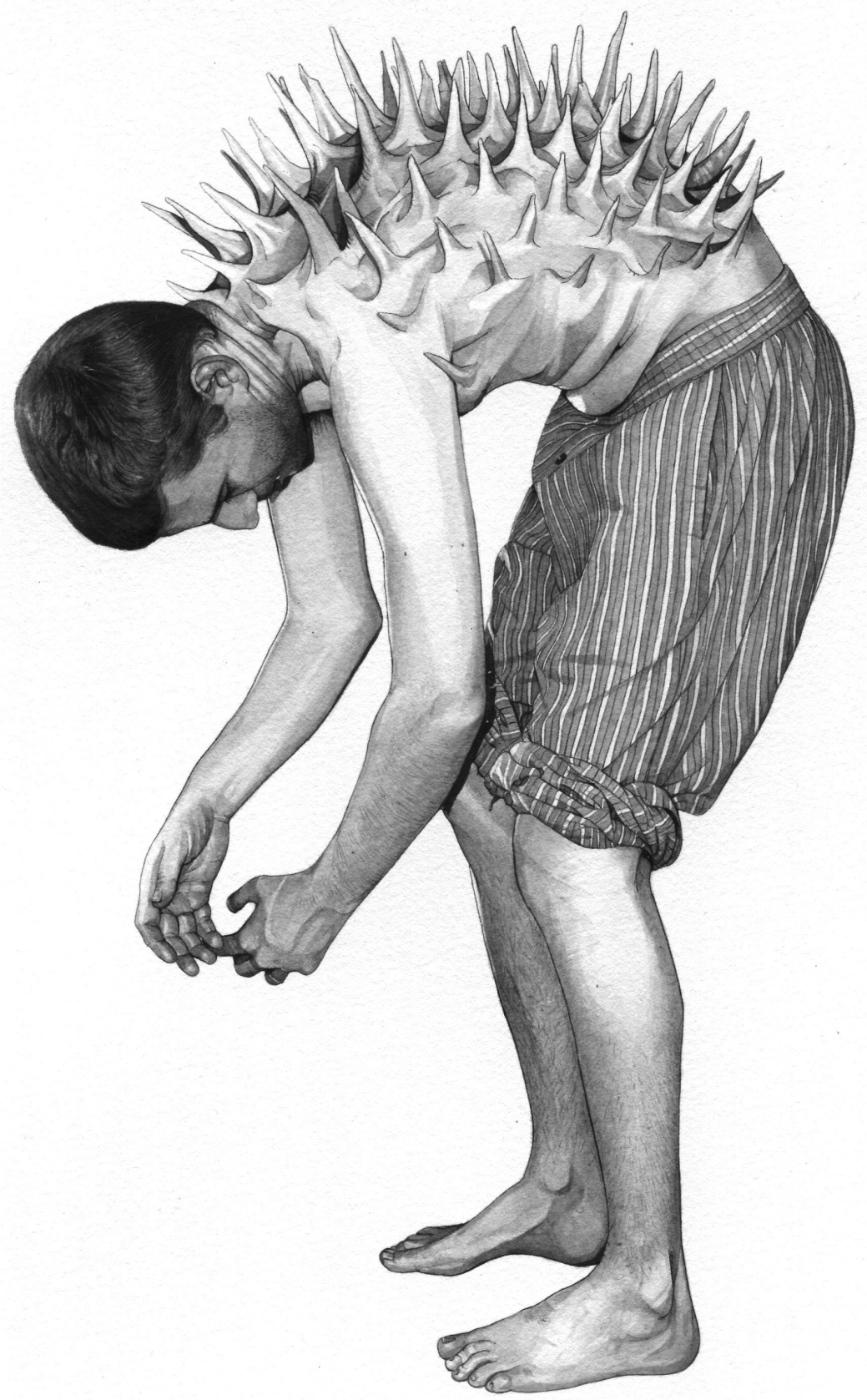




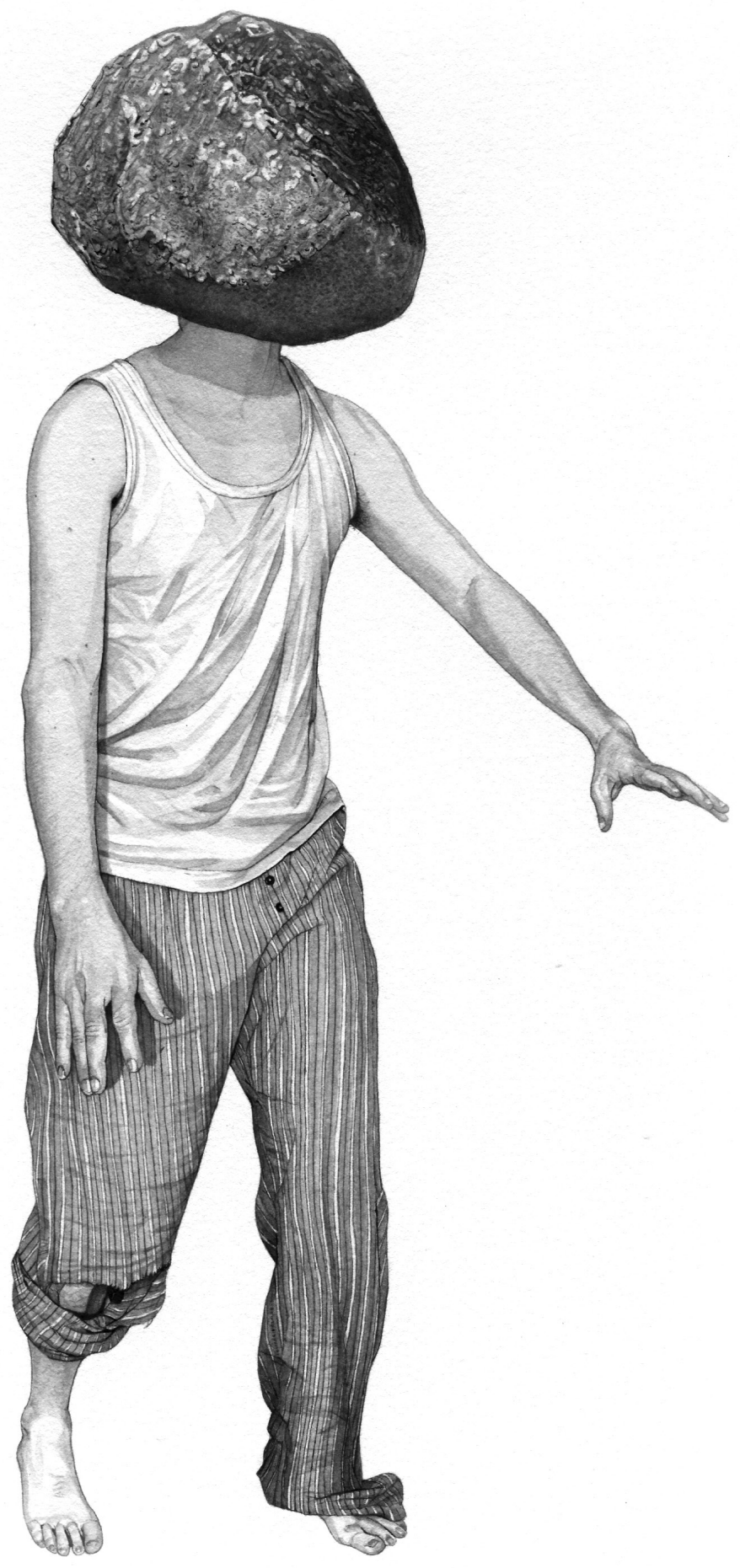




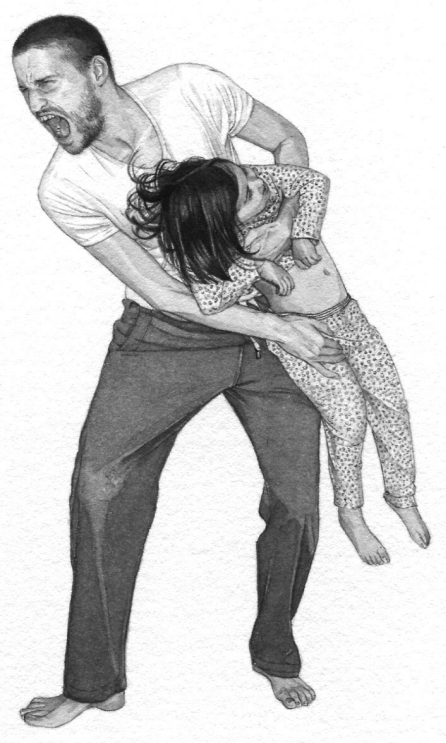


L i

है is

(

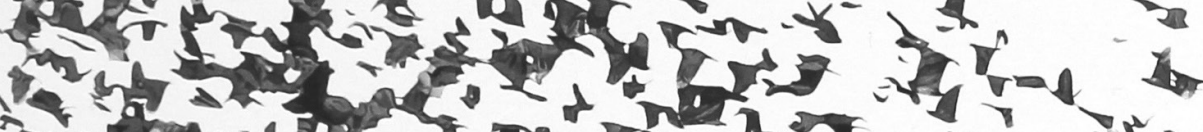

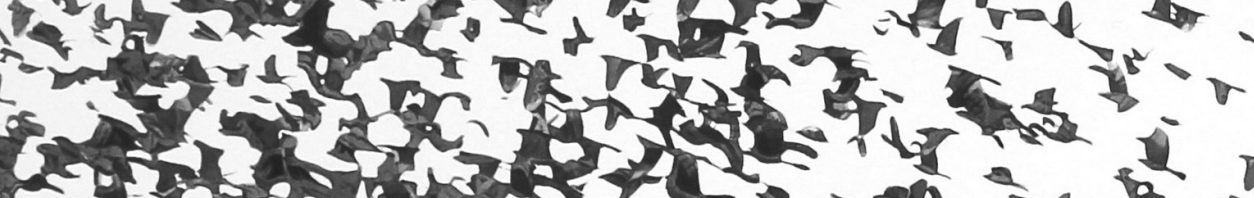

in the

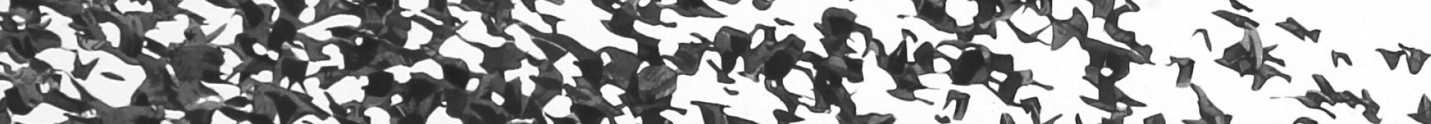
v.

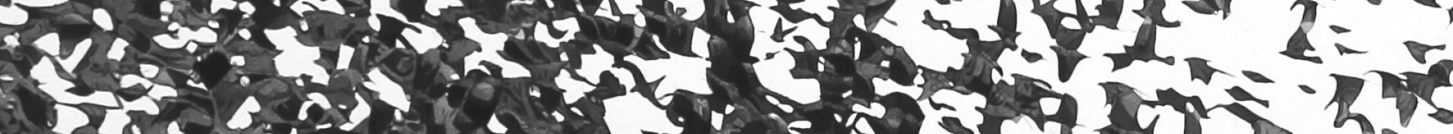

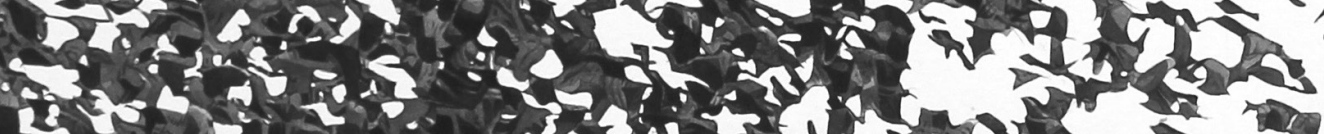
(4)

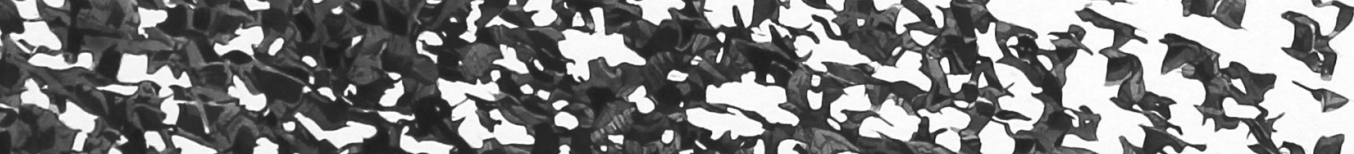

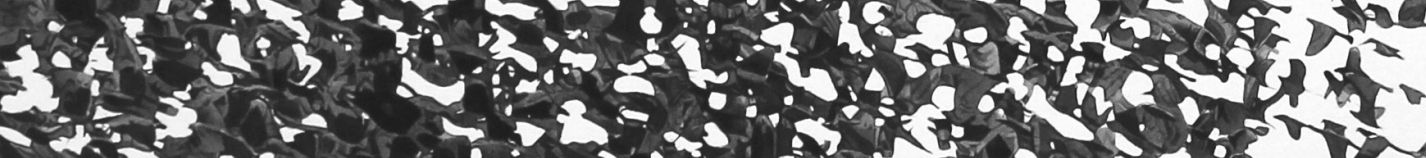



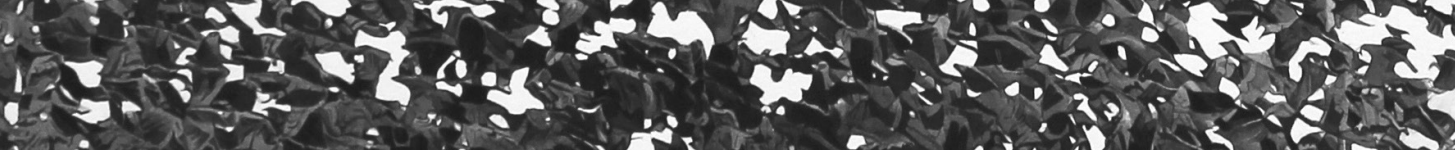

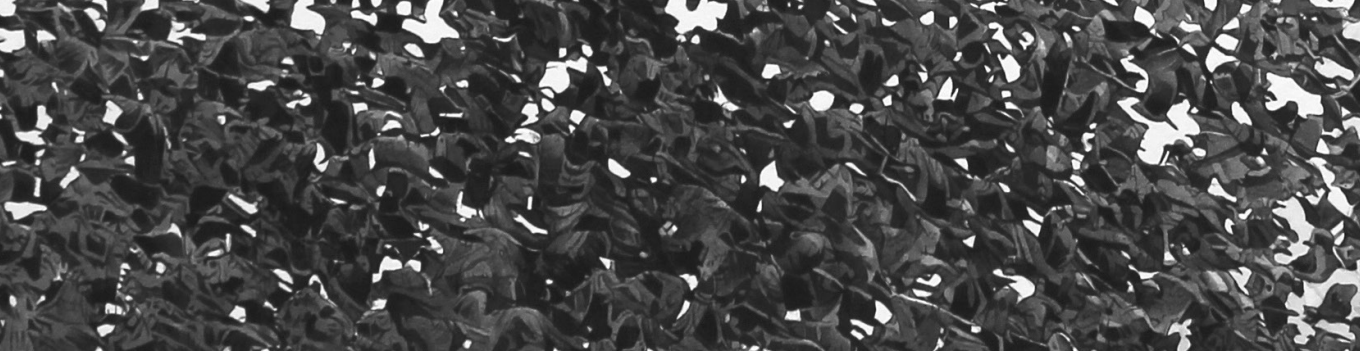

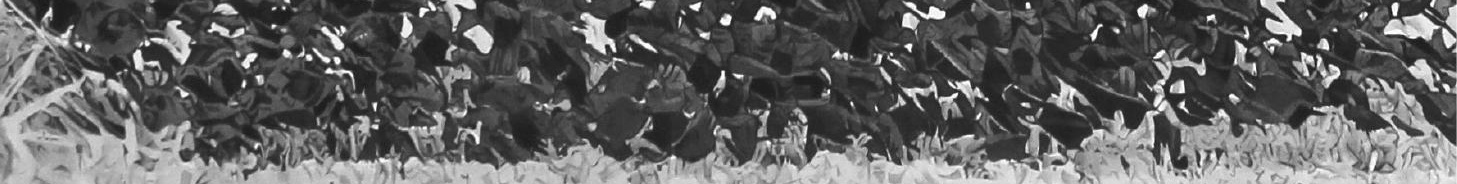




$$
\hbar
$$




$$
t^{4}
$$




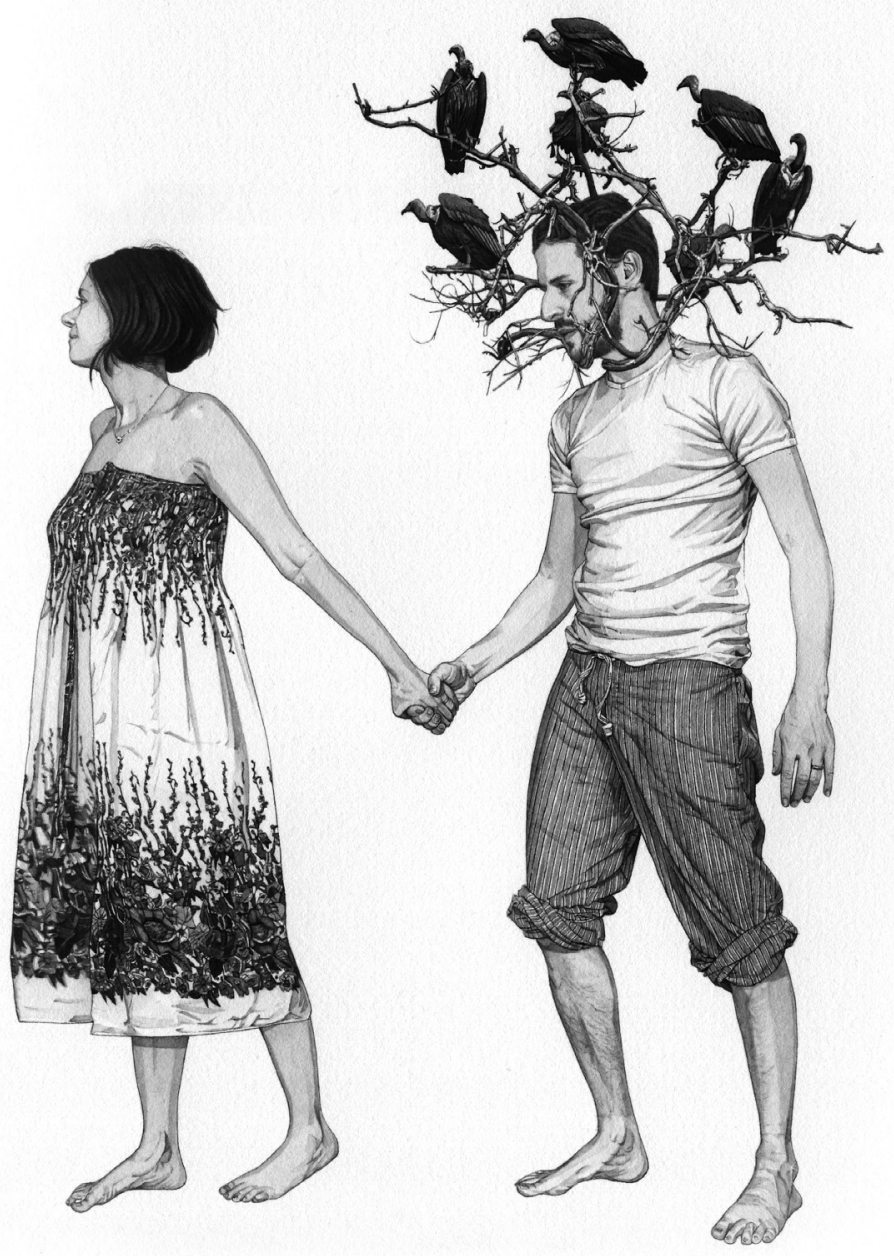



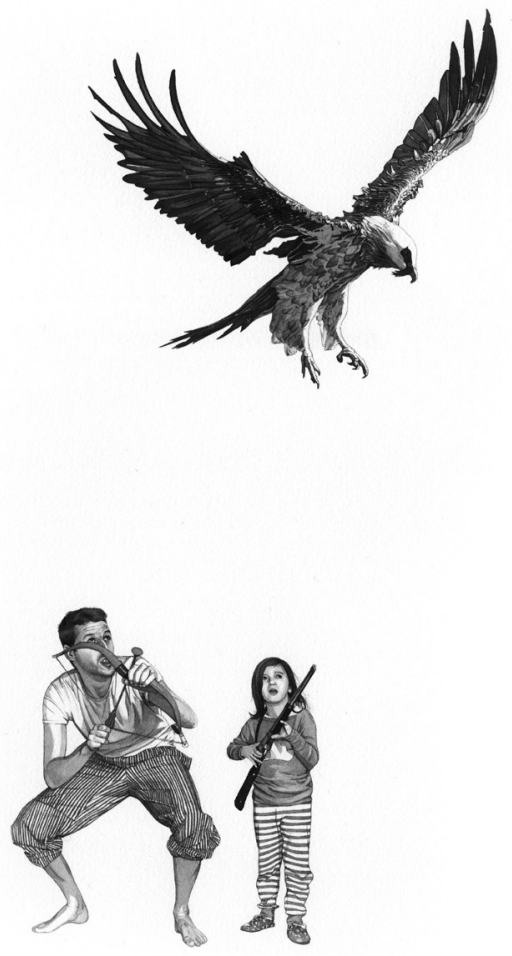


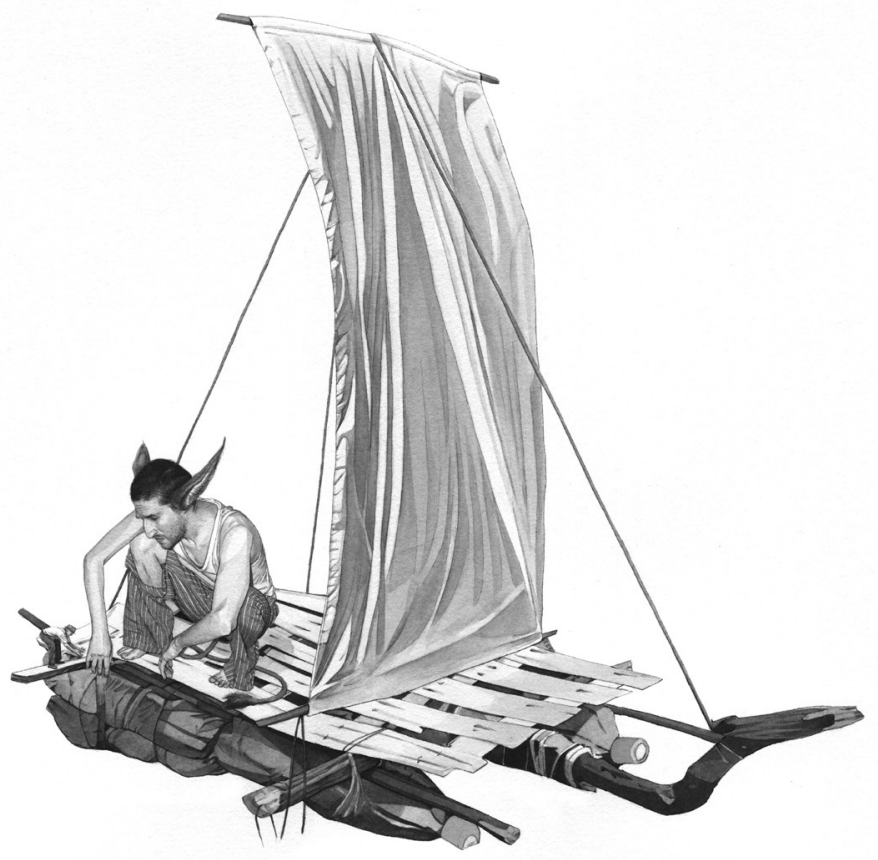




$$
4
$$




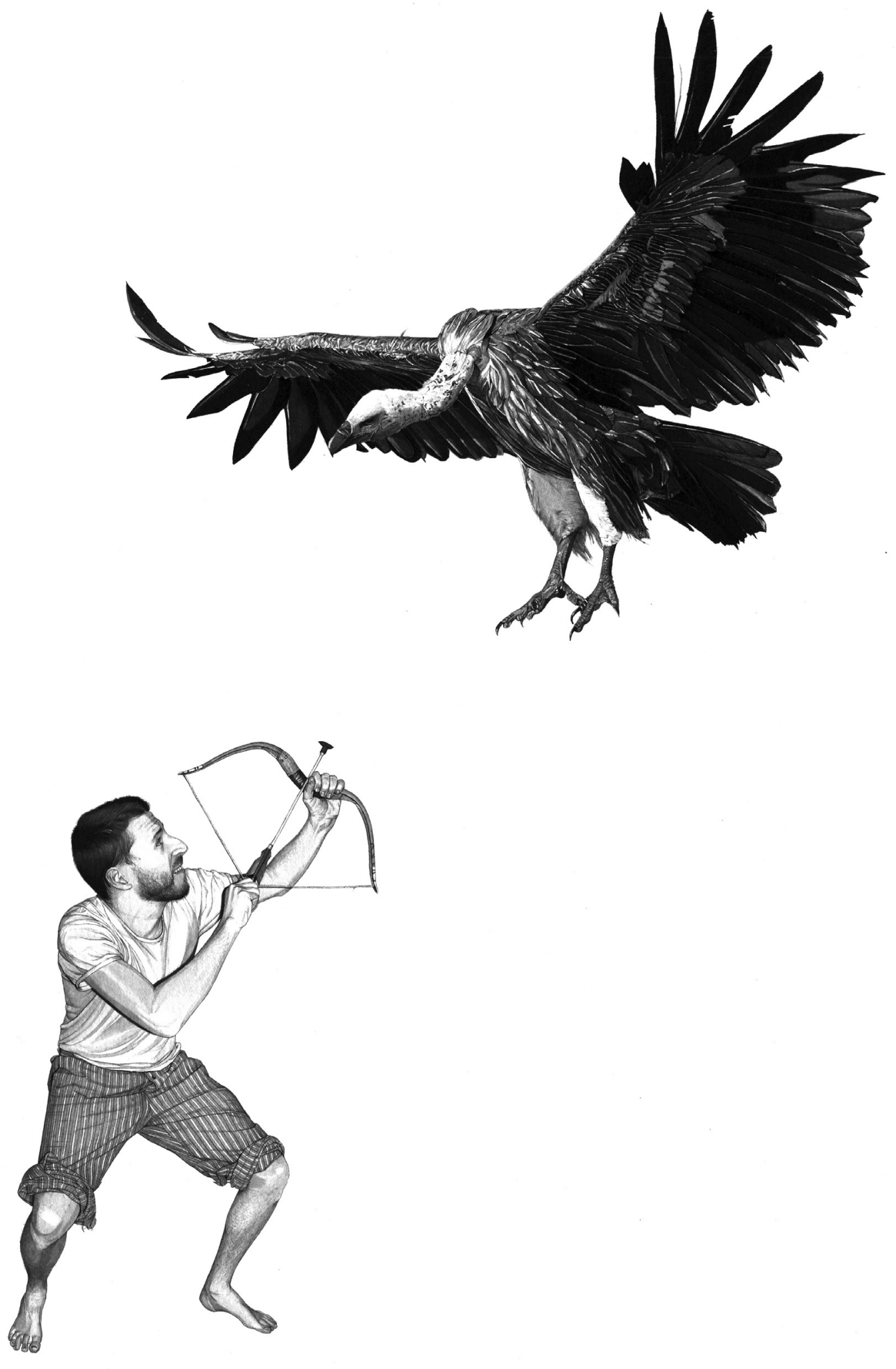


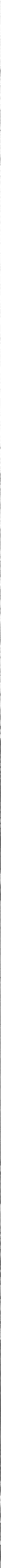









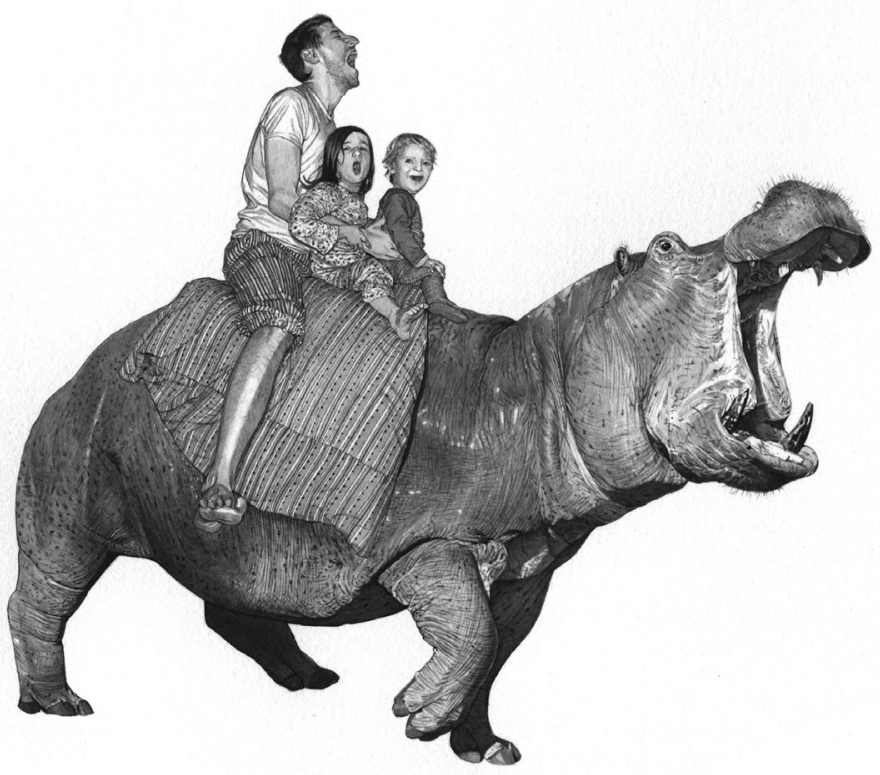




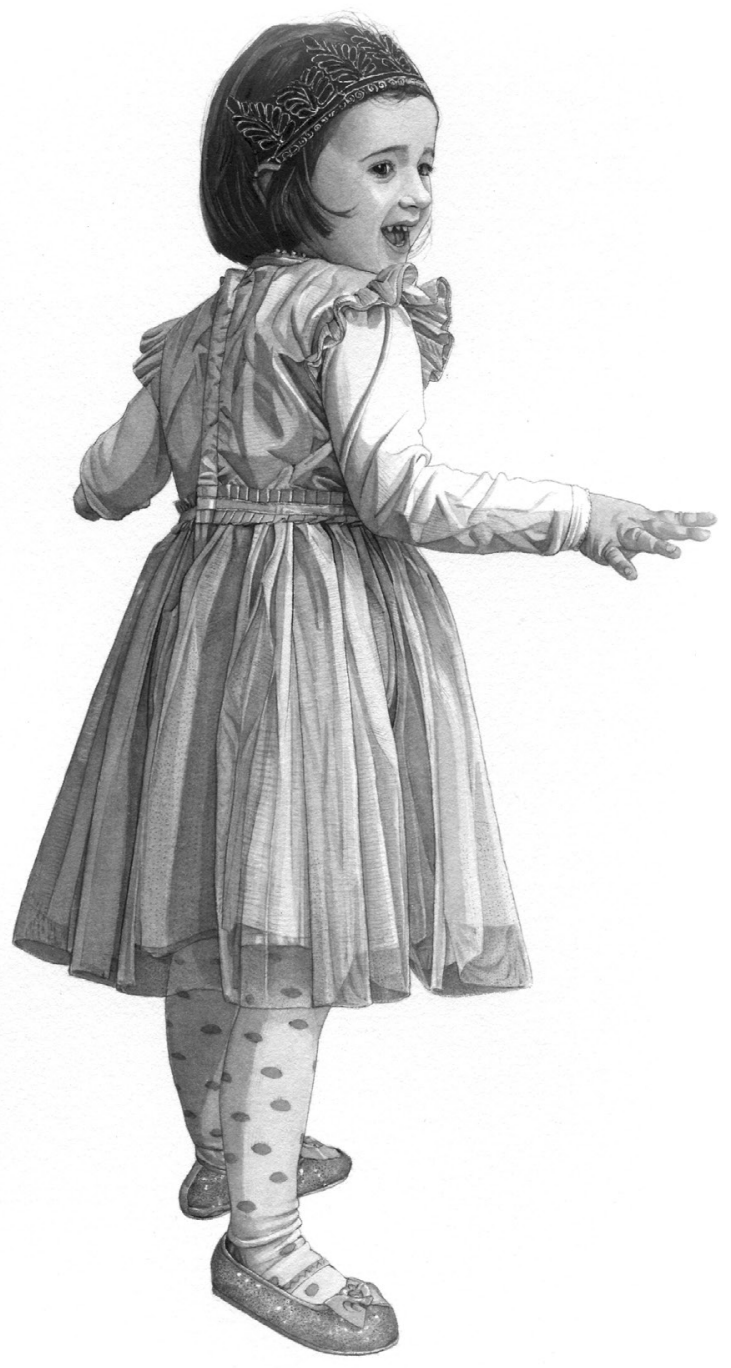




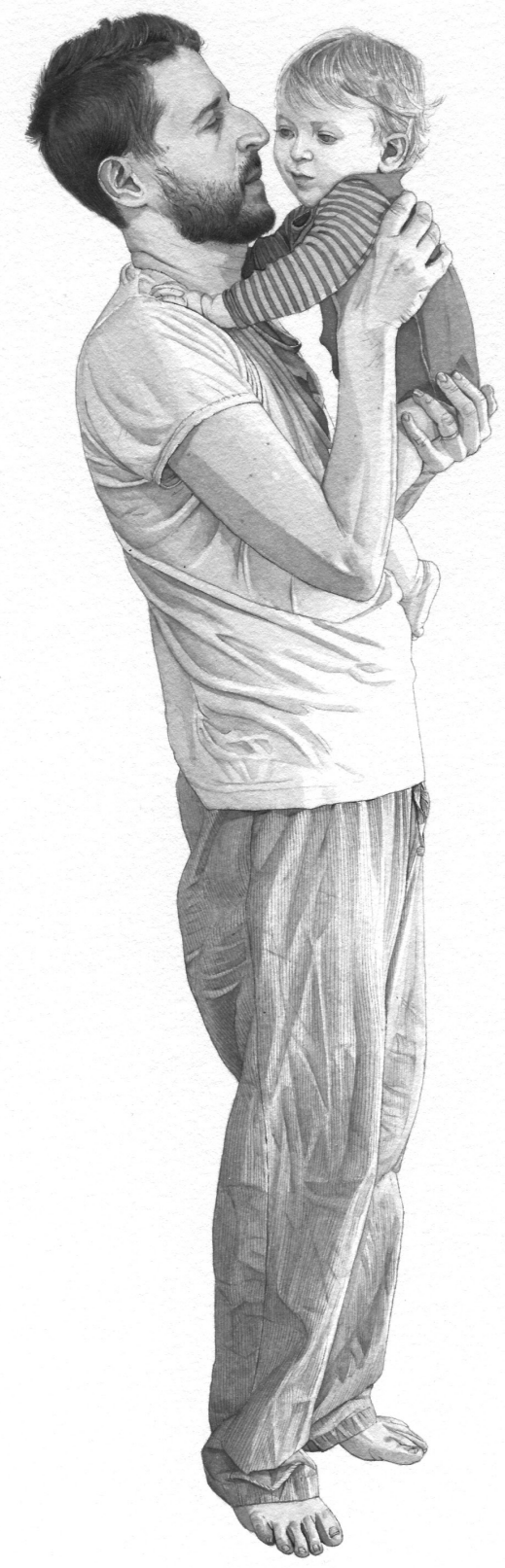




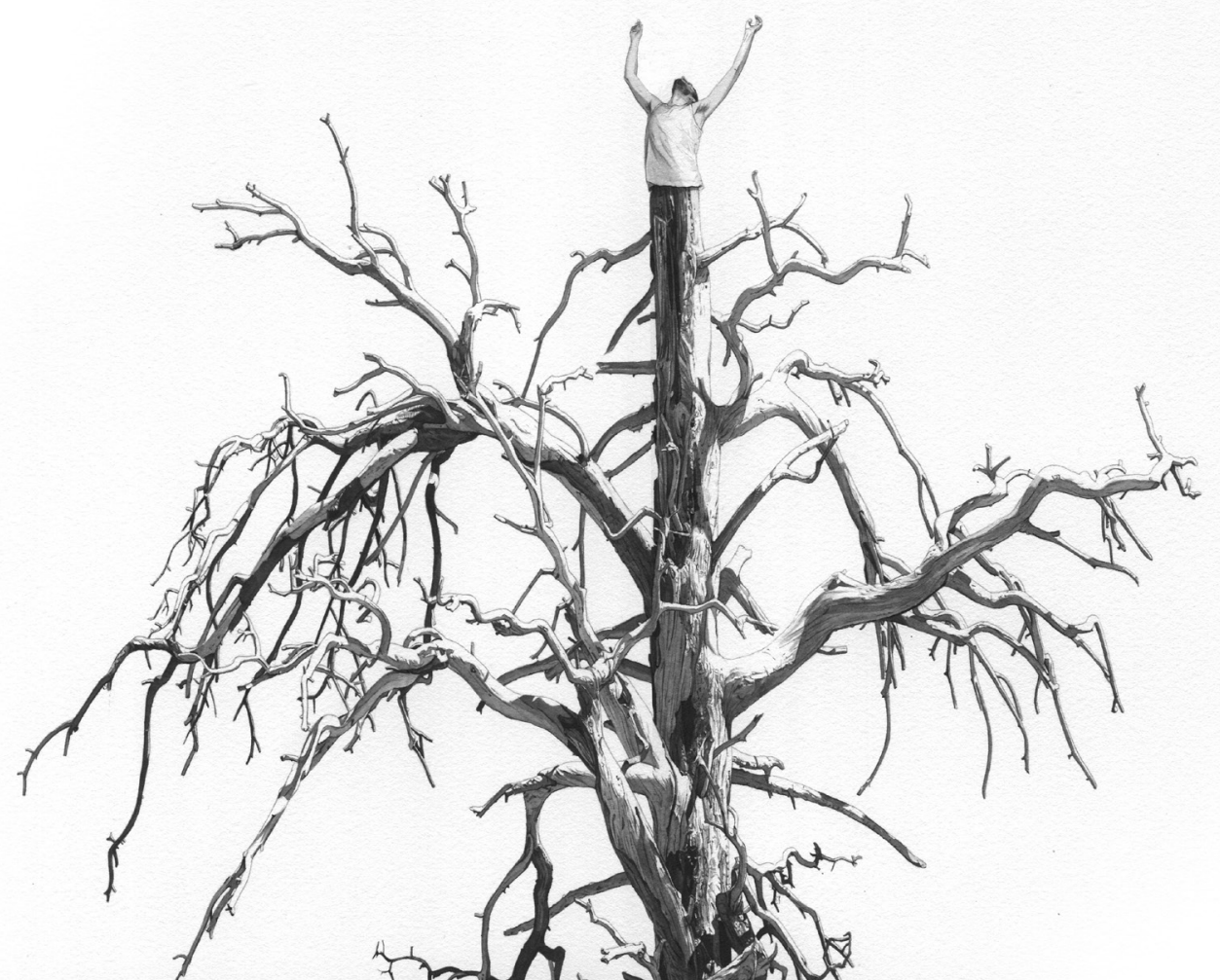


